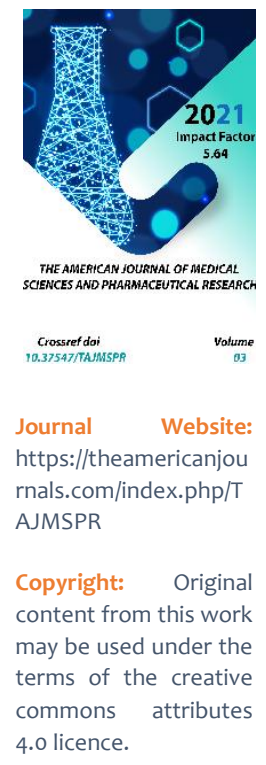

\title{
Use Of Information And Communication Technology In Primary Sanitary Institutions. Implementation Of A Single Medical Information-Analysis System For Pregnant Contingents
}

Ergashev Akrom Abdukhalilovich

Applicant For The Department Of Public Health And Healthcare Management, Tashkent Pediatric Medical Institute, Uzbekistan

Iskandarova Shakhnoza Tulkinovna

Scientific Supervisor, Professor Of The Head Of The Department Of Public Health And Health Management, Tashkent Pediatric Medical Institute, Uzbekistan

\section{ABSTRACT}

The purpose of the study: development of the Program using ICT for the decreed contingent and the creation of a unified medical information and analytical system, at the stage of transition to compulsory medical insurance.

Materials and methods. Research methods: will be studied the following employees of school educational and district medical institutions ( $\mathrm{SHOU}, \mathrm{RMU}$ ) who periodically underwent medical examination in the Kibray district of the Tashkent region.

Results and Discussions: The study found that in 2019, the Qibray District Medical Association Medical Commission examined only 4,992 workers or 4.3 percent (116061) of the able-bodied population of Qibray District, of which 29 were diagnosed with some form of the disease. Or only 0.58 percent of the diagnosed diseases are women.

Conclusions: based on an in-depth analysis of the contingent, further studies will create an electronic database on the categories, groups, age, disease and frequency of the contingent contingent in Qibray district of Tashkent region.

\section{KEYWORDS}

Medical examination, Wellness, medical culture, medical examination, medical institution, number of population, medical workers. 


\section{INTRODUCTION}

The work carried out is carried out within the framework of the Decree of the President of the Republic of Uzbekistan dated May 24, 2017 No. UP-5052 "On measures to further improve state policy in the field of employment and radically increase the efficiency of labor bodies", Resolution of the President of the Republic of Uzbekistan dated 06.05.2017 No. PP-2960 "On measures to increase the personal responsibility of the heads of local executive authorities and territorial bodies of the economic complex for the effectiveness and efficiency of the work to ensure employment of the population", the widespread introduction of the "e-health" system and the creation of the UMIAS RMO corresponds to the strategic goal of the development of the system health care provided by the CONCEPT for the development of the health care system of the Republic of Uzbekistan for 2019-2025.

\section{PURPOSE OF THE STUDY}

Development of the Program using ICT for the decreed contingent and the creation of a unified medical information and analytical system, at the stage of transition to compulsory health insurance.

\section{MATERIALS AND METHODS}

The material of the research will be studied the following employees of school educational and district medical institutions, who periodically took part in a medical examination in the Kibray district of the Tashkent region.

In addition, the scale in the context of specialties and the time of passing medical examinations by category will be studied in accordance with the Regulations on the procedure for conducting medical examinations of employees [Registered by the
Ministry of Justice of the Republic of Uzbekistan on August 29, 2012, Registration No. 2387].

\section{RESULTS AND DISCUSSIONS}

Currently, the Order of the Minister of Health of the Republic of Uzbekistan on the approval of the regulation on the procedure for conducting medical examinations of employees dated July 10, 2012, No. 200 [Registered by the Ministry of Justice of the Republic of Uzbekistan on August 29, 2012, Registration No. 2387] is in force. Healthcare of the Republic uses various forms and reports in paper form, in particular, there are no information systems and databases in the RMO, containing significant amounts of information on medical examinations, the primary collection of which is carried out manually, which implies the possibility of making significant mistakes due to the "human factor".

In the field of medical care, the decreed contingent is absent and the ICT system for the collection, storage, processing, transmission and use of information in electronic form is not implemented. Weak implementation of information and communication technologies in the health care system, excessive volumes of introduction of medical documentation in paper form do not allow to quickly track the progress and ensure the effective implementation of decisions, and also cause unnecessary bureaucracy and high costs. (Appendix No. 1 to the Decree of the President of the Republic of Uzbekistan dated 07.12.2018 No. UP-5590 CONCEPT of the development of the health care system of the Republic of Uzbekistan for 2019-2025).

According to the data obtained, the population of the Kibray district as of 01.01.2020 is 200,447, 
of which women - 101,872, and men - 98,575, out of the total population, minor children under 18 make up 66,930. Of these, 38,820 are girls, and boys - 28110 (Diagram 1).

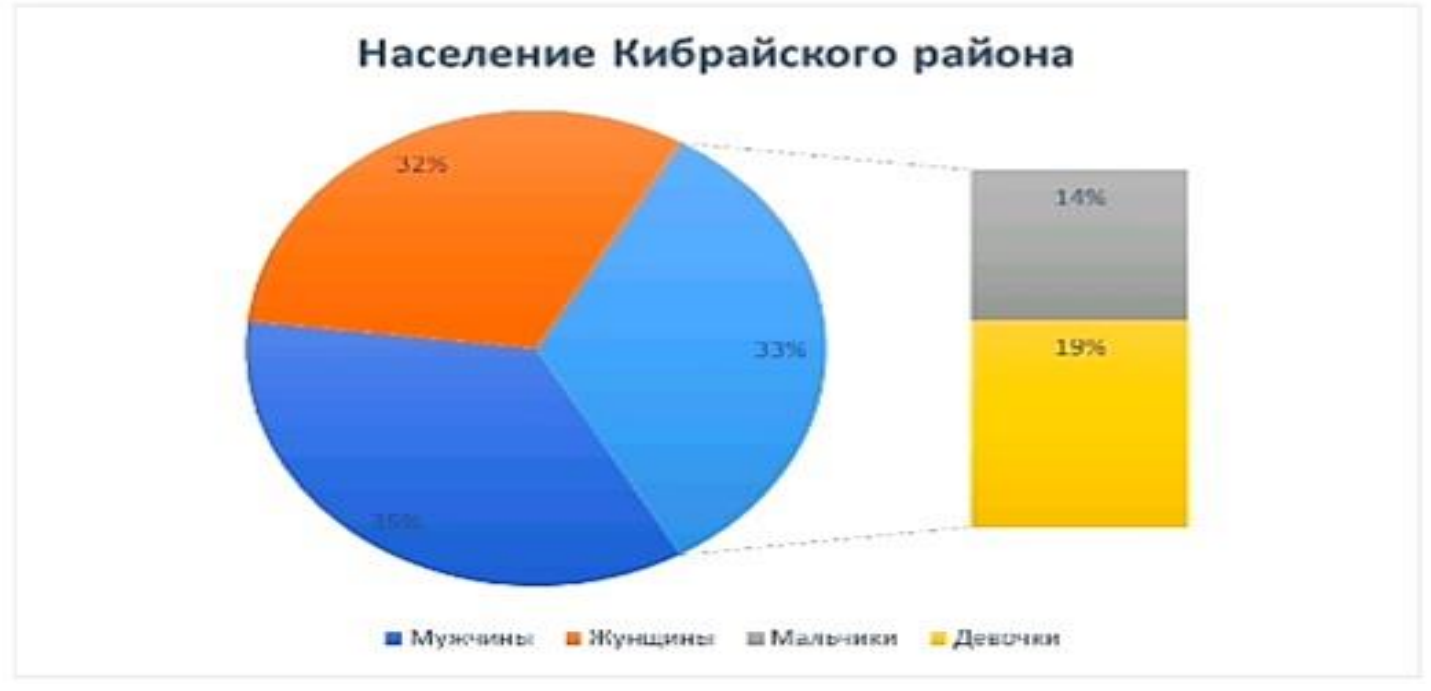

Diagram 1. Population of Kibray region

The obtained statistical data on the state of the number of medical workers showed us that 11 medical institutions function on the territory of the Kibray district of the Tashkent region, where 2260 medical workers conduct their professional activities, of which 1992 are women, and 268 are men (Diagram 2).
Taking into account the ratio of the population to the number of doctors and nurses in this area, we can conclude that the number of doctors and nurses is not able to meet the existing needs of the population in medical personnel.

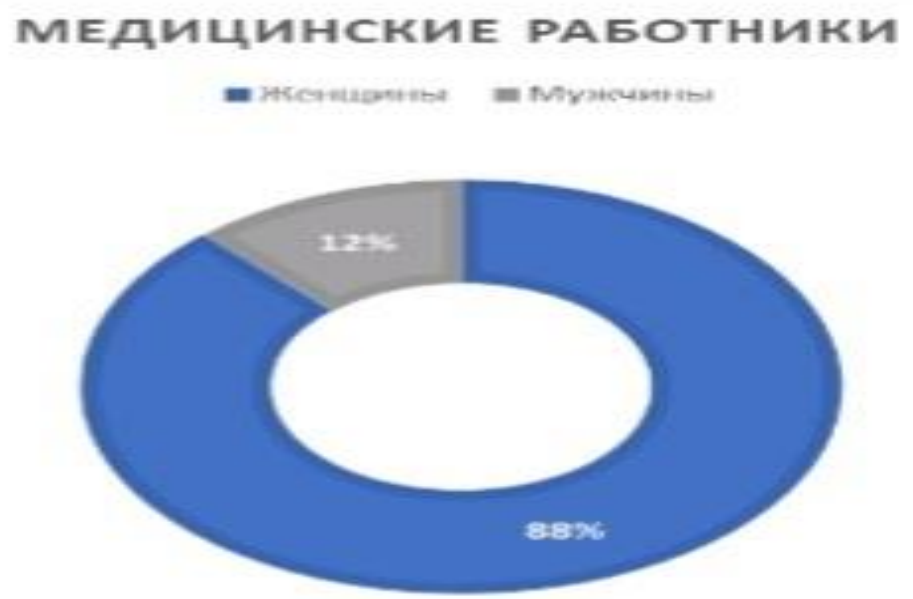

Diagram 2. Health care workers 
The population of working age is 116,061 people, of which women under 55 are 58,871 people, of which men under 60 are 57,190 people. (Diagram 3)

\section{Населения трудоспособного}

ш мужчиндо 60 лет шенщиндо 55 лет

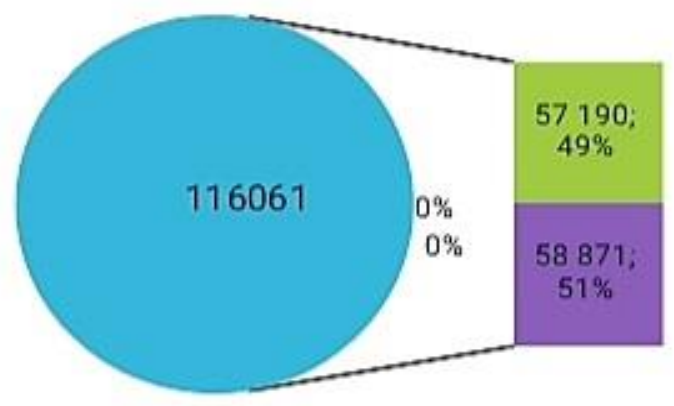

Diagram 3. Population working capacity

Preschool educational institutions of the Kibray district comprise 42 institutions, 996 employees work in it, 837 of them are women, 159 of them are men. There are 56 people working and retired in these institutions, 49 of them are women, 7 of them are men. (Diagram 4)

\section{Количество работников в дошкольных образовательных учреждениях}

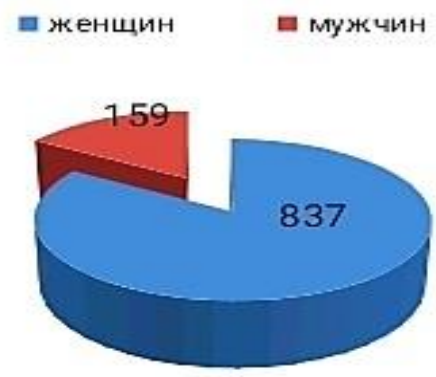




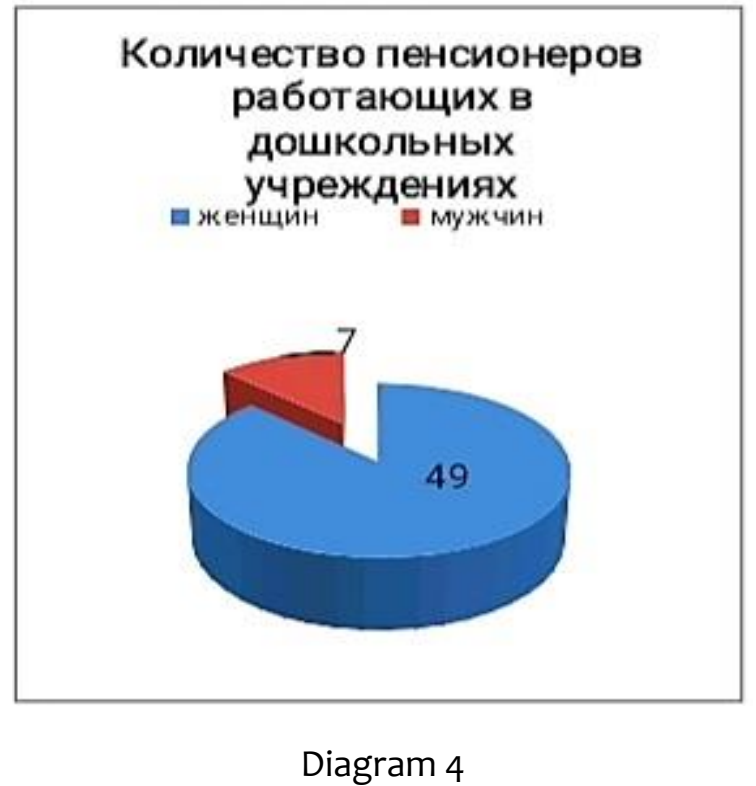

The number of children in preschool institutions is only 5,400 children, or $8 \%$ of the total number of children under 18 years of age. There are 48 school educational institutions, 1655 employees work in it, of which 1100 are

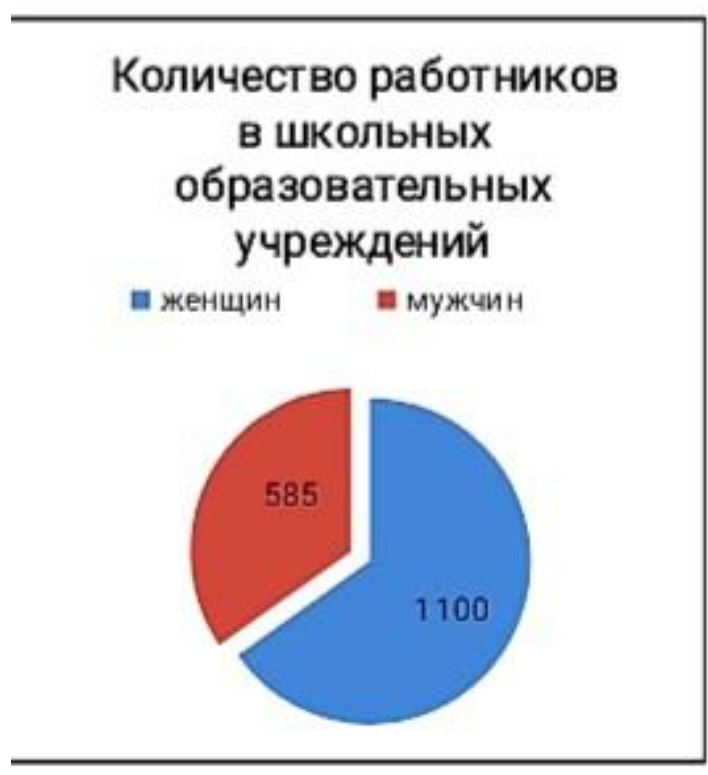

\section{Diagram 5}

At the time of the study, 120 doctors work in the central multidisciplinary polyclinic (CMP), women, 585 of them are men. The number of children enrolled in school institutions is only 22881 children $34.18 \%$ of the total number of children under 18 years old, (Diagram 5 ).

\section{Количество школ и учащихся} детей

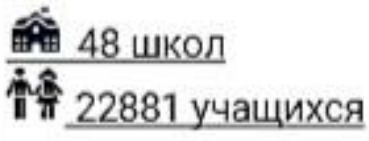

ш Количество детей до 18 лет

п Количество детей обучающихся в школьныхучреждений

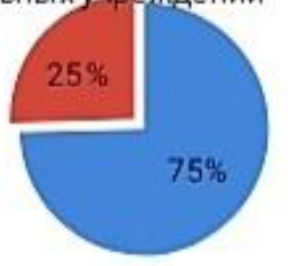

of which 80 are women, which is $66 \%$ of the total, and 40 are men, which is $33 \%$ of the total 
number of employees, the number of junior medical personnel is -145 people, of them women-142, of them men-3, employees and

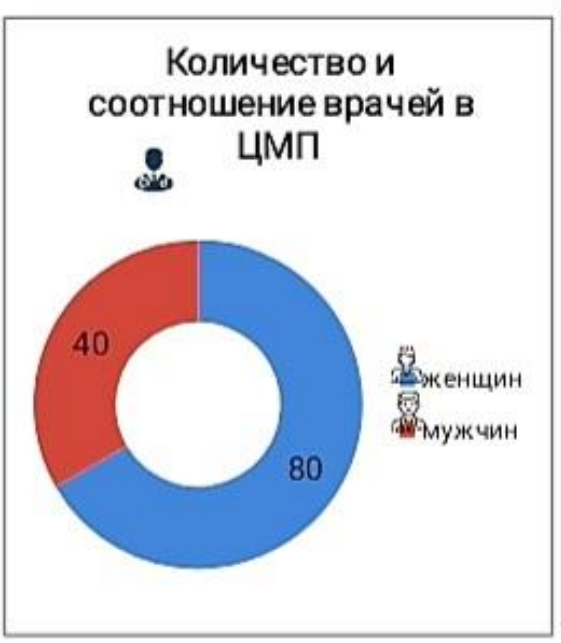

nurses working in the CMP is -27 people, of them women-27, of them men-0. (Diagram 6).

Diagram 6

The number of rural family polyclinics (RSP) is only 5 , the number of doctors working in them is -52 people, of which 35 are women doctors, and 13 are men. Junior medical personnel are

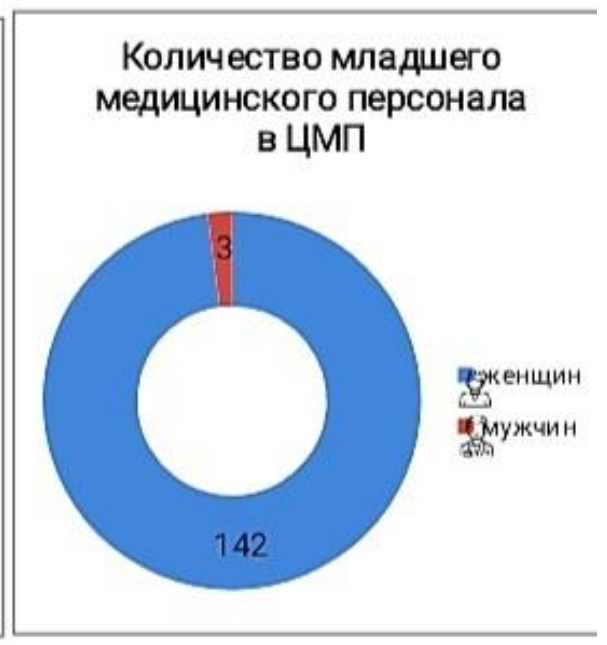

Количество младшего

в ЦМП

214 women, employees and nurses working in the SSP are -38 people, of whom 20 are women, 18 of them are men (Diagram 7)

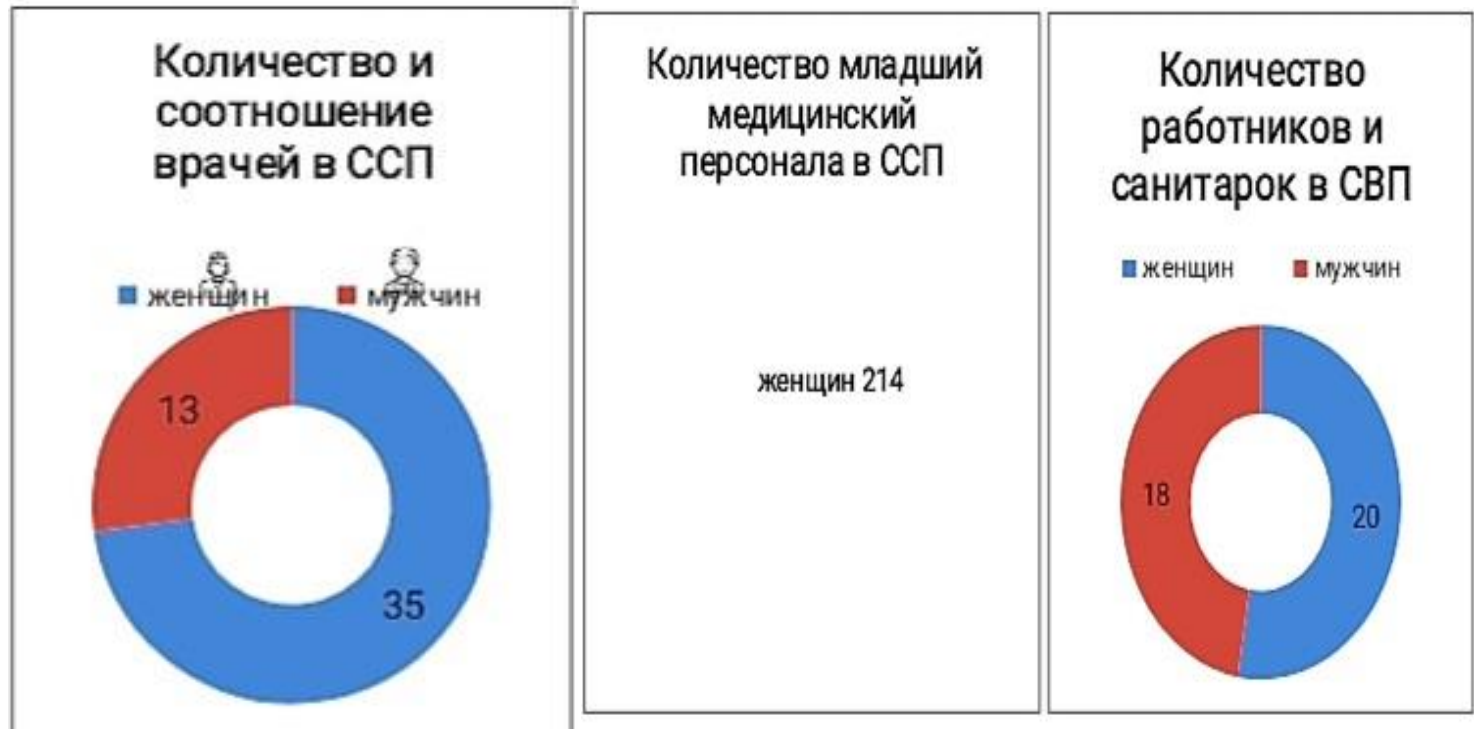

Diagram 7 
The number of Rural Medical Posts (SVPs) is only $-4,18$ doctors work in total, of which 16 are women doctors, and 2 are doctors, junior medical personnel is -108 people, of which -108

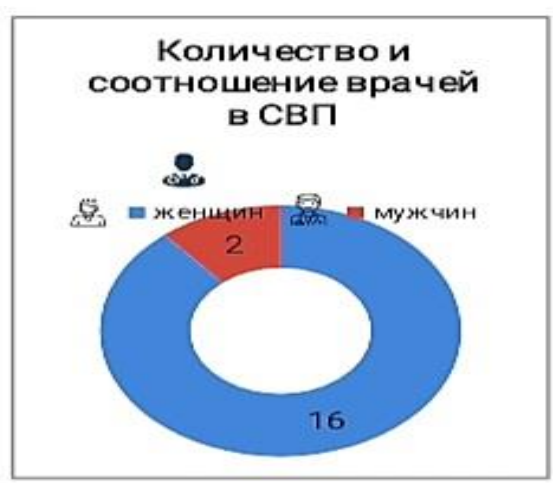

women are employees and nurses working in SVPs is -21 people, of which women -10, of which men -11, (Diagram 8).

\section{Количество работников и санитарок в СВП}

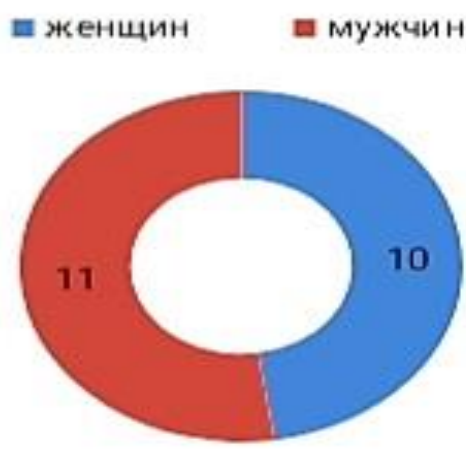

\section{Diagram 8}

The Central District Hospital ( $\mathrm{CRH}$ ) has a total of $-1,173$ doctors serve the population, of which women -128 doctors, and 45 men speak, the number of junior medical personnel is -1020 people, of which women -930, of which men -
90, employees and nurses working in the Central District Hospital make up -300 people, of whom -275 are women, 25 of them are men (Diagram 9). 

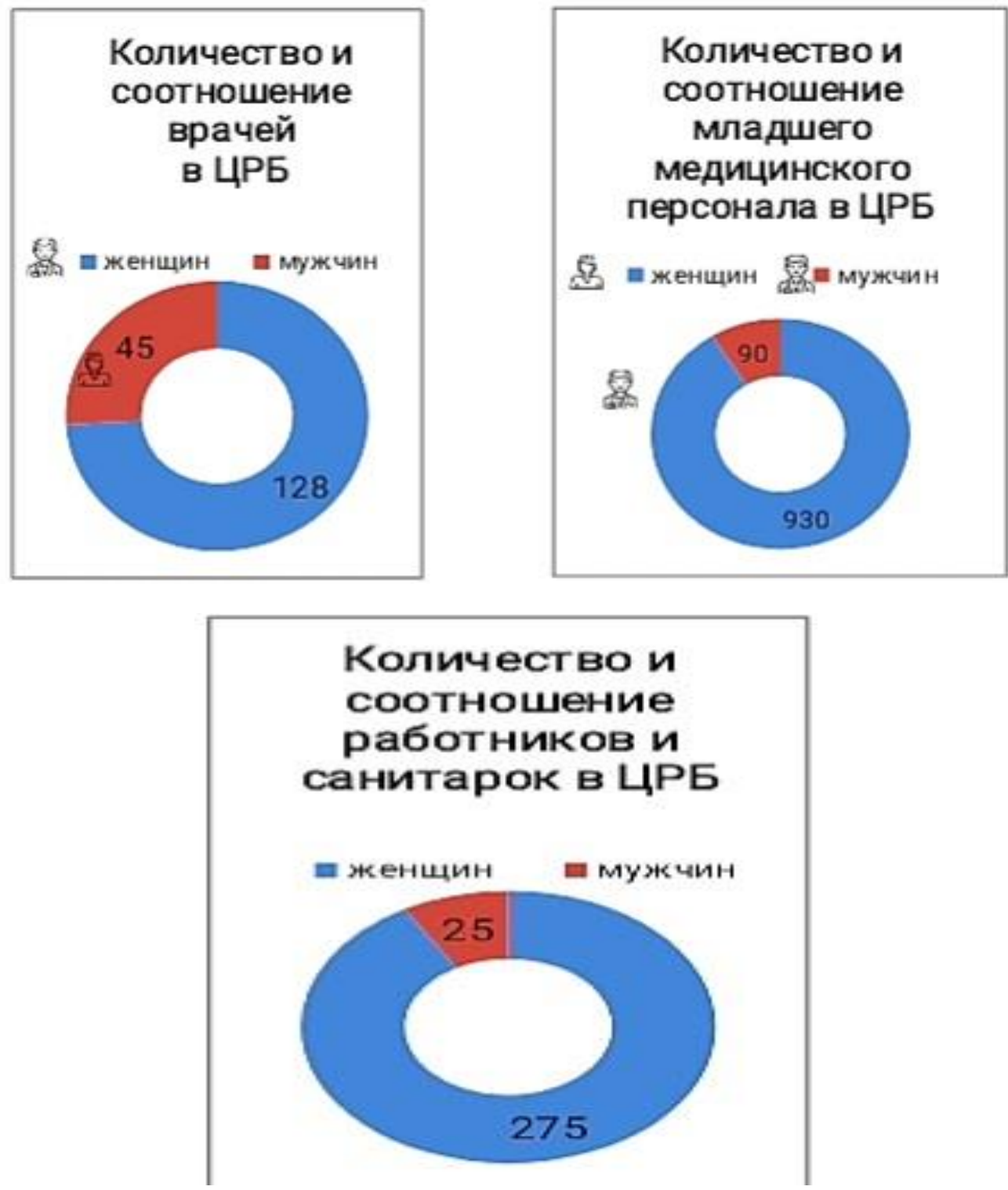

Diagram 9

At the same time, from the side of the regional SES in 2019, some shortcomings were revealed in the above institutions, in particular, 43 employees of these institutions did not undergo a timely medical examination, of which a fine of 9,872,930 soums was collected, and 40 employees were strictly warned. in order to timely undergo medical examinations.During the study, it was revealed that by the medical commission of the RMO of the Kibray region in 2019, only 4992 workers were examined, or $4.3 \%$ of the working population of the Kibray region (116061), of which only 29 workers, or $0.58 \%$, were diagnosed with diseases, of which women up to 55 years old 20 people, $0.4 \%$ of them men up to 60 years old 9 people $0.18 \%$. An interesting fact is that no referrals were issued to 
employees of the above organizations for inpatient treatment in 2019 (Diagram 10).

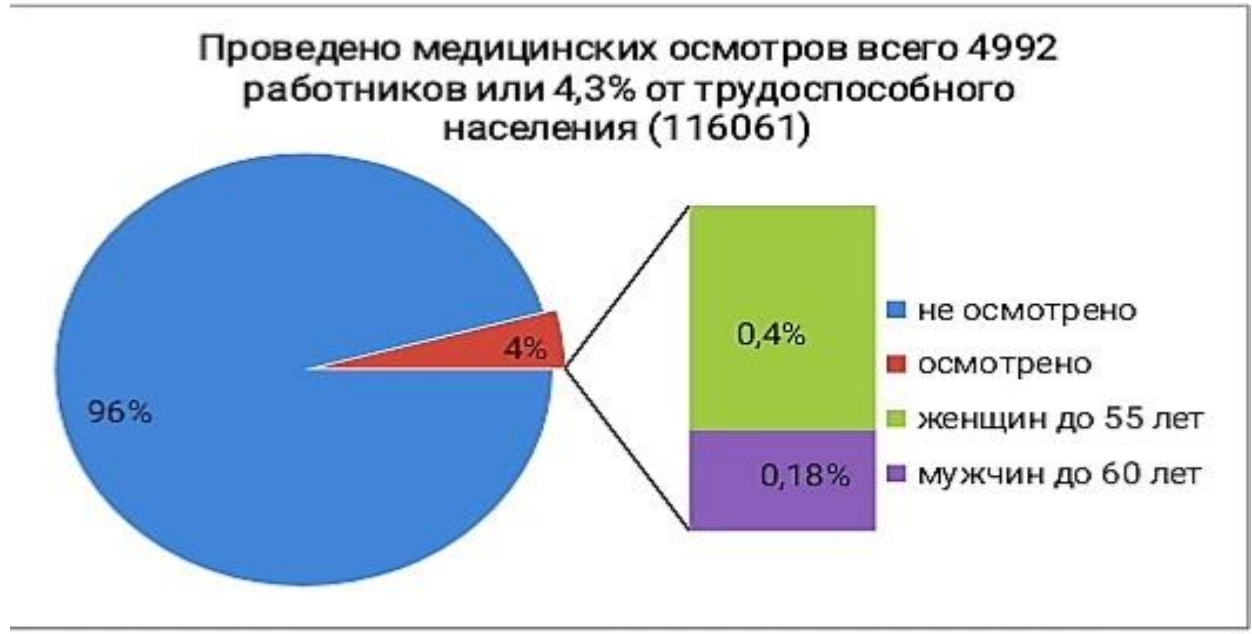

\section{Diagram 10}

The number of referrals issued for sanatoriumresort treatment is only 44 employees or $0.88 \%$ of those who underwent a medical examination, of which women under 55 years old -38 people $0.76 \%$ of whom men under 60 years old -6 people $0.12 \%$, persons with disabilities-o, as well as the issuance of referrals to rest homes, sanatoriums and dispensaries, 12 of them are women under 55, 7 of them are men under 60.

The total number of nurses and doctors who completed the questionnaire was 534, of which 60 were men and 474 were women, ie $88.7 \%$ were women. Out of a total of 2,260 medical staff, 534 were trained, ie $23.5 \%$.

The staff of general secondary education institutions is 339, of which 22 are men (6.4\%) and 317 are women, ie $93.5 \%$ are women. A total of 339 out of 2553 employees of general secondary education institutions were surveyed, ie $13.2 \%$.
Thus, the analysis of the current situation in the organization of hygiene education of population groups, and the prevention of infectious and parasitic diseases, shows that it is necessary to develop a system of training in hygiene education and training of high-level descriptive contingent in order to improve the sanitary culture of the population, including:

- Development of a comprehensive interagency program for the protection and promotion of socially important professions and their health, based on the coordination of activities of health, educational institutions and organizations, which includes three interrelated sections: information, health and research.

- Development of measures to involve professors and high-level specialists of nearby medical higher education institutions in the organization of medical examinations; 
- Ensuring the organization and conduct of activities for the introduction of medical examinations, especially for women, the expansion of medical examinations;

- Early detection of diseases and prevention of their chronic form through the organization of quality medical examinations and laboratory-instrumental examinations;

- Introduction of e-medicine on the "Descriptive contingent", this system allows the employee to organize targeted and quality medical examinations using accurate information and statistics on a number of issues, such as when and in what specialty to conduct timely medical examinations, expert opinions and recommendations, requirements and needs creates convenience.

\section{CONCLUSIONS}

Further study on the basis of an in-depth analysis of the decreed contingent will make it possible to create a database (DB) of categories of persons of the decreed contingent living in the Kibray district of the Tashkent region, by groups, by age, by morbidity and frequency of medical examination in the context of preschool, school educational and regional medical institutions. Identification of factors hindering the development of mechanisms for effective interdepartmental interaction and cooperation in the field of health protection of the decreed contingent of the Kibray district of the Tashkent region.

\section{REFERENCES}

1. Abdelkrim M. Problems of voluntary health insurance: scientific publication / $M$. Abdelkrim, V. I. Pylenko // Pharmacy. - M., 2014.

2. Abdullahodjaeva M. S. The value of information and communication technologies in the implementation of the program "Protection of mothers and children": scientific publication // National model of maternal health and child in Uzbekistan: "Healthy mother - healthy child" xb.theses / International symposium.-T .: IPTD "Uzbekistan", 2011. 16op. - Tashkent.

3. Abdullahodjaeva M.S. The introduction of information and communication technologies in the pathological service / M. S. Abdullakhodzhaeva, M. Oberholzer // Medical Journal of Uzbekistan. - Tashkent: - 2007.

4. Azanov V. G. Assessment of the effects of the introduction of a medical information system by medical workers on the example of three health care institutions of the Krasnoyarsk Territory: scientific publication / V. G. Azanov, A. V. Shakhov // Doctor and information technologies. M., 2016.

5. Askarov D. A. Organizational and methodological foundations for creating a unified state information system in the field of health care: scientific publication / D. A. Askarov // Issues of economics and management for health managers. - M., 2016.

6. Bobrov A. V. Information technologies in occupational medicine: scientific 
publication / A. V. Bobrov // Occupational

medicine and industrial ecology. - M., 2017

7. Issues of compulsory insurance of civil liability of medical organizations to patients: scientific publication // Issues of economics and management for health managers. - M., 2015.

8. Eight priority tasks for the development of Russian health care for the period until 2020: scientific publication // Issues of economics and management for healthcare leaders.-M., 2010.

9. Daminov B. T. Electronic education in medicine / B. T Daminov, Sh. P. Ashirbaev, -I. P. Vikhrov // Bulletin of the Association of Doctors of Uzbekistan. - Tashkent, 2017.

10. Information and analytical technologies in the health care management system: scientific publication // Issues of economics and management for health care managers. -M., 2019.

11. The first steps of informatization of the oncology service in Uzbekistan: scientific publication / S. N. Navruzov, D. A. Alieva// Congress of oncologists of Uzbekistan, third: collection of materials (May 14-16, 2015, St. Tashkent). - Tashkent, 2015 .-- P. 226. 